\title{
Hemocyten van de honingbij (Apis mellifera), een babylonische spraakverwarring
}

\section{Hemocytes of the honeybee (Apis mellifera), a babylonian confusion of tongues}

\author{
${ }^{1,2}$ C. Van Herzele, ${ }^{\#, 1}$ H. Nauwynck, ${ }^{\#, 2}$ D.C. de Graaf \\ ${ }^{1}$ Department of Translational Physiology, Infectiology and Public Health, \\ Faculty of Veterinary Medicine, Ghent University, \\ Salisburylaan 133, 9820 Merelbeke, Belgium \\ ${ }^{2}$ Department of Biochemistry and Microbiology \\ Faculty of Sciences, Ghent University, \\ Krijgslaan 281 S2, 9000 Ghent, Belgium \\ \# Shared seniorship
}

cato.vanherzele@ugent.be

\section{AMENVATTING}

Het afgelopen decennium werden er wereldwijd alarmerend hoge sterftecijfers bij honingbijen geregistreerd. Deze trend is problematisch omdat de bij een cruciale rol speelt als bestuiver in natuurlijke en agrarische ecosystemen. Deze problematiek wordt veroorzaakt door verschillende stressoren met de varroamijt (Varroa destructor) als belangrijkste. Onafhankelijk van de oorzaak is het eindresultaat echter hetzelfde: het immuunsysteem begeeft het waardoor de bij en bij uitbreiding het bijenvolk sterft. Om dit fenomeen te kunnen begrijpen, is het belangrijk een grondige kennis te bezitten van hun immuunsysteem. Deze is namelijk verantwoordelijk voor de bescherming van bij en bijenvolk tegen deze verschillende stressoren. Ondanks het grote belang van de bij en het huidige hoge aantal wetenschappelijke publicaties over honingbijen, is er nog maar weinig onderzoek naar hun cellulaire immuniteit verricht. In dit artikel worden de obstakels van het hemocytenonderzoek beschreven, zoals traumatische collectiemethoden, gebrek aan standaardisatie en onvoorzichtige extrapolatie (van insecten en leeftijden). Als laatste wordt een beknopt overzicht gegeven van de vermoedelijke hemocytentypes en hun functies.

\section{ABSTRACT}

In the last decade, alarmingly high honeybee mortality rates have been registered. This trend is problematic because honeybees play a crucial role in natural and agricultural ecosystems. These increased mortality rates have several causes with the varroa mite (Varroa destructor) as the most important cause. However, independently of its cause, the end result is the same: the honeybee's immune system fails and the whole hive dies. To improve insights into this phenomenon, thorough understanding of the immune system is of major importance. The immune system protects the honeybee and the hive against the different causes of mortality. Despite the honeybee's great importance and the substantial amount of scientific publications, research on their cellular immunity is still limited. In this article, the different hemocyte research obstacles are described, such as traumatic collection methods, lack of standardization and uncareful extrapolation (of insects and ages). Lastly, a short overview of the probable hemocyte types and functions is given. 


\section{INLEIDING}

In België schommelt de wintersterfte van honingbijen boven de aanvaardbare 10\%. In 2012/2013 werd een record van 32,4\% geregistreerd (https://www. anses.fr/en/content/european-epilobee-programme: laatst geconsulteerd op 25/10/2021). Alhoewel dit aanzienlijk probleem al meer dan een decennium door onderzoekers en imkers wereldwijd onder de aandacht wordt gebracht, is er nog altijd geen oplossing voor handen (Chaimanee et al., 2012; VanEngelsdorp et al., 2012; Jacques et al., 2017; Gray et al., 2019). De bijensterfte heeft meerdere oorzaken, zoals de aanwezigheid van pesticiden, virussen, bacteriën, parasieten en nutritionele deficiënties. Dit maakt deze problematiek enorm complex (Ravoet et al., 2015; Negri et al., 2016; McMenamin et al., 2018). Al deze factoren veroorzaken het falen van het immuunsysteem van de bij en van het gehele bijenvolk, met sterfte als gevolg.

Honingbijen bezitten enkel een aangeboren immuunsysteem. Deze is opgedeeld in een cellulaire en humorale immuniteit. Het humorale immuunsysteem bestaat uit antimicrobiële peptiden, reactieve intermediairen van zuurstof en stikstof en de complexe enzymatische cascades die coagulatie en melanisatie regelen (Lavine en Strand, 2002). Er is overlap met het cellulaire immuunsysteem. De cellulaire immuniteit bestaat uit hemocyten die circuleren in de hemolymfe. Het gebrek aan een verworven immuniteit wordt steeds meer in vraag gesteld (Gourbal et al., 2018). Bij de honingbij werd bijvoorbeeld "trans-generational immune priming" vastgesteld (López et al., 2014). Er werd een verhoogde overleving bij larven vastgesteld, waarvan de moeder reeds eerder met Amerikaans vuilbroed (Paenibacillus larvae) was besmet. Deze nieuwe inzichten zouden potentieel beter begrepen kunnen worden, indien de kennis van de cellulaire immuniteit bij de honingbij wordt uitgebreid.

\section{VERSCHILLENDE ADDERS ONDER HET GRAS}

Ondanks de inspanningen is er tot op heden geen eensgezindheid bereikt over zowel de naamgeving als de types hemocyten (Klowden, 2013). Verscheidene oorzaken liggen hier aan de basis. Ten eerste wordt de indeling steeds gebaseerd op andere criteria. Zo worden hemocyten ingedeeld op basis van morfologie, gedrag in vitro en binding met lectinen, antistoffen en verschillende fluorescente moleculen (Van Steenkiste, 1987; de Graaf et al., 2002; Marringa et al., 2014; Negri et al., 2014; Burritt et al., 2016; Gábor et al., 2017; Richardson et al., 2018; Gábor et al., 2020). Ten tweede zijn hemocyten dikwijls zeer labiel, waardoor ze in vitro snel melaniseren of desintegreren (Negri et al., 2014). Bovendien kunnen functionele adaptaties de morfologie van een type sterk beïnvloeden. Voor bijna elk insect kunnen grote aantallen overgangsstadia tus- sen de verschillende types voorkomen, waardoor het moeilijk wordt om verschillende types uit elkaar te houden (Jones, 1962; Van Steenkiste, 1987). Ten derde is er een grote verscheidenheid tussen de verschillende insectenordes. In tegenstelling tot vele andere insecten bezit de honingbij ook een belangrijke sociale immuniteit, bijvoorbeeld het poetsgedrag. Deze heeft mogelijk een grote invloed op de individuele cellulaire immuniteit (Van Steenkiste, 1987; Gábor et al., 2020). Gábor et al. (2020) stelden een veel lager fagocytosepercentage vast bij hemocyten van de honingbij dan bij deze van de fruitvlieg (Drosophila melanogaster). Hierdoor zouden bijen minder afhankelijk zijn van hun individuele immuniteit. Ook bevatten bijen slechts een derde van de immuungenen aanwezig bij de D. melanogaster (Hultmark, 2003; Gadau et al., 2012). Of dit gelinkt is aan hun sociale immuniteit, is nog niet bekend (Barribeau et al., 2015). Extrapolatie tussen insecten moet dus steeds voorzichtig gebeuren. Ten vierde is er, net zoals bij zoogdieren, een variatie in hemocyten die samenhangt met de ontwikkeling van het dier. Het ontwikkelingsstadium, de leeftijd, de kaste, de voeding en de hormonale balans hebben alle een invloed op het bloedbeeld (Van Steenkiste, 1987). Bij honingbijen wordt niet gesproken over geslachten maar over kasten. Er zijn drie honingbijkasten, i.e. de koningin, de dar en de werkster. Darren staan in voor de bevruchting van de koningin die daarna de rest van haar leven eitjes legt. De werksters verzorgen verschillende taken binnen en buiten de kast. Honingbijen zijn holometabole insecten, d.w.z. dat ze een volledige metamorfose ondergaan. De juveniele honingbij komt uit het ei als larve en wordt via het popstadium een volwassen insect. Deze metamorfose gaat niet alleen gepaard met drastische morfologische maar ook fysiologische veranderingen. Bijgevolg kan verwacht worden dat de hemocyten ook een drastische verandering ondergaan (Van Steenkiste, 1987; Amdam et al., 2005; Gätschenberger et al., 2013; Negri et al., 2014, 2016; Hystad et al., 2017; Ravaiano et al., 2018; Yelkovan et al., 2021). Adulte werksters spenderen de eerste drie weken in de kast, waar ze het broed verzorgen. De laatste vier levensweken foerageren ze. Gätschenberger et al. (2013) toonden aan dat deze verschillende levensfasen gepaard gaan met een veranderde capaciteit om nodulen te vormen. Zo kunnen oudere bijen minder nodulen vormen dan jongere bijen, en winterbijen kunnen geen nodulen vormen. Nodulatie is een cellulaire reactie tegen lichaamsvreemde partikels (biotisch en abiotisch) die terechtkomen in het hemocoel (Van Steenkiste, 1987). Ook vertonen oudere bijen een drastische daling in het aantal hemocyten (Zuk en Stoehr, 2002; Schmid et al., 2008). Niet alleen kasten maar ook het ras heeft een effect (Saltykova et al., 2005; Ravoet et al., 2015; Ali et al., 2017). Ten vijfde bestaat er tussen honingbijen een individuele variatie, een fenomeen dat ook bij de mens en andere diersoorten bekend is. Zo werd er tussen individuele oesters een variatie bekomen net 
zoals bij mensen (Ashton-Alcox en Ford, 1998). Ook werd er bij de schorpioenvlieg (Panorpa vulgaris) een individuele variatie gevonden in het totaal aantal hemocyten en algemene fagocytose capaciteit (Kurtz et al., 2000). Ten zesde hebben verscheidene externe factoren, zoals honger, verwonding, ziekten, verschillende geneesmiddelen en pesticiden, een effect op het algemene bloedbeeld (Van Steenkiste, 1987). Zo werd aangetoond dat neonicotinoïden een reductie geven van de hemocytenconcentratie, de inkapselingsreactie en de antimicrobiële activiteit (Brandt et al., 2016; De Smet et al., 2017). Er werd ook een verminderd hemocytenaantal gevonden bij bijen geïnfecteerd met de bacterie Serratia marcescens-stam sicaria (Burritt et al., 2016). Hystad et al. (2017) onderzochten de relatie tussen vitellogenine, dat een belangrijk hormoon is bij de metamorfose van de honingbij, en fagocytose, maar vonden zeer variabele resultaten tussen de verschillende kolonies. Als laatste heeft de keuze van de (histologische) technieken een grote invloed op de morfologie en dus ook op de indeling van de hemocytentypes. In de literatuur worden voor de honingbij vooral May-Grünwald Giemsa-, Wright's Giemsa-, Giemsa- of hematoxyline-eosinekleuring gerapporteerd. Zelden worden andere kleuringen, zoals periodic-acid-schiffkleuring of Sudan-zwartkleuring gebruikt (Jones, 1962; Van Steenkiste, 1987; Mohandes et al., 2010; Marringa et al., 2014; Sherif, 2017; Richardson et al., 2018). Geen enkele individuele methode is echter voldoende voor de studie van de verschillende types bij verschillende insectensoorten. Bovendien geven verschillende technieken frequent tegenstrijdige informatie over de typologie, het aantal, de distributie en functie. Daarnaast worden cellen frequent incorrect verzameld en behandeld. Zo wordt er zelden gebruik gemaakt van anticoagulantia en/of koeling (Van Steenkiste, 1987; Negri et al., 2013; Hystad et al., 2017; Ravaiano et al., 2018; Yelkovan et al., 2021). Deze zijn echter essentieel om de morfologie en functie van de hemocyten te kunnen behouden doordat ze de stolling en melanisatie van de hemolymfe voorkomen. Hemolymfecollectie gebeurt vaak zeer traumatisch. Frequent worden ledematen uitgetrokken en wordt hemolymfe verzameld door druk te zetten op thorax en/of abdomen (Borsuk et al., 2017; Migdał et al., 2020). Het creëren van een wonde zorgt voor contaminatie van de hemolymfe en het vrijstellen van gevaarsignalen die de hemocyten activeren. Om de functie van hemocyten te achterhalen, worden frequent in-vitrostudies uitgevoerd. Er is echter nog steeds geen eensgezindheid bereikt over de correcte media (de Miranda et al., 2013; Genersch et al., 2013; Negri et al., 2014; Guo et al., 2020). Bovenstaande factoren in combinatie met een gebrek aan onderzoeksinteresse heeft geleid tot een chaotische, incomplete en waarschijnlijk foute opdeling van de hemocyten. Deze kennis is nochtans belangrijk om de honingbijsterfte te begrijpen en te kunnen tegengaan.

\section{HEMOCYTEN}

In de literatuur worden verschillende hemocyten beschreven. Er is echter geen eensgezindheid over het al dan niet bestaan van elk beschreven type. In Tabel 1 en Figuur 1 wordt een overzicht van de verschillende hemocytkarakteristieken weergegeven. Er is een enorm grote morfologische variatie zichtbaar. Dit is deels te wijten aan het feit dat de indeling gebaseerd is op de algemene indeling van Gupta (1979) of Jones (1962), die zich hebben gebaseerd op morfologische kenmerken van verschillende insectenhemocyten die frequent onder traumatische omstandigheden geïso-

Tabel 1. Overzicht van de in de literatuur beschreven hemocytkarakteristieken bij de honingbij (Uit: Gupta, 1979; Van Steenkiste, 1987; Mohandes et al., 2010; Richardson et al., 2018; Yelkovan, et al., 2021). PL4 = plasmatocyt-subtype 4 beschreven door Van Steenkiste (1987).

\begin{tabular}{|c|c|c|c|c|c|c|c|}
\hline & Grootte & Morfologie & $\begin{array}{l}\text { Uitstul- } \\
\text { pingen }\end{array}$ & $\begin{array}{l}\text { Nucleus } \\
\text { locatie }\end{array}$ & $\begin{array}{l}\text { Nucleus } \\
\text { morfologie }\end{array}$ & Granulen & $\begin{array}{l}\text { Nucleus/ } \\
\text { cytoplasma } \\
\text { ratio }\end{array}$ \\
\hline Prohemocyt & $6-8 \mu \mathrm{m}$ & Rond - ovaal & Nee & Centraal & Rond - ovaal & Nee - weinig & Groot \\
\hline Plasmatocyt & $8-14 \mu \mathrm{m}$ & $\begin{array}{l}\text { Rond - ovaal - } \\
\text { fusiform }\end{array}$ & Soms & $\begin{array}{l}\text { Centraal- } \\
\text { excentrisch }\end{array}$ & $\begin{array}{l}\text { Rond - ovaal - } \\
\text { ontdubbeld }\end{array}$ & $\begin{array}{l}\text { Enkel PL4 - } \\
\text { nee }\end{array}$ & Groot \\
\hline Granulocyt & $13-21 \mu \mathrm{m}$ & Rond - ovaal & Soms & $\begin{array}{l}\text { Centraal- } \\
\text { excentrisch }\end{array}$ & Rond - ovaal & $\mathrm{Ja}-$ nee & Klein \\
\hline Sferulocyt & Variabel & Rond & Soms & $\begin{array}{l}\text { Centraal- } \\
\text { excentrisch }\end{array}$ & Onduidelijk & Onduidelijk & Klein \\
\hline Adipohemocyt & $15-23 \mu \mathrm{m}$ & Rond - ovaal & Soms & $\begin{array}{l}\text { Centraal- } \\
\text { excentrisch }\end{array}$ & Variabel & $\mathrm{Ja}-$ nee & Klein \\
\hline Oenocytoïd & $18-19 \mu \mathrm{m}$ & Rond - ovaal & Nee & $\begin{array}{l}\text { Centraal- } \\
\text { excentrisch }\end{array}$ & $\begin{array}{l}\text { Rond - ovaal - } \\
\text { ontdubbeld }\end{array}$ & $\begin{array}{l}\text { Ja (zwak) - } \\
\text { nee }\end{array}$ & Klein \\
\hline Coagulocyt & $5-10 \mu \mathrm{m}($ kern $)$ & Rond - ovaal & Nee (meestal) & $\begin{array}{l}\text { Centraal - } \\
\text { excentrisch }\end{array}$ & $\begin{array}{l}\text { Rond - ovaal - } \\
\text { - los }\end{array}$ & Nee & Klein \\
\hline
\end{tabular}




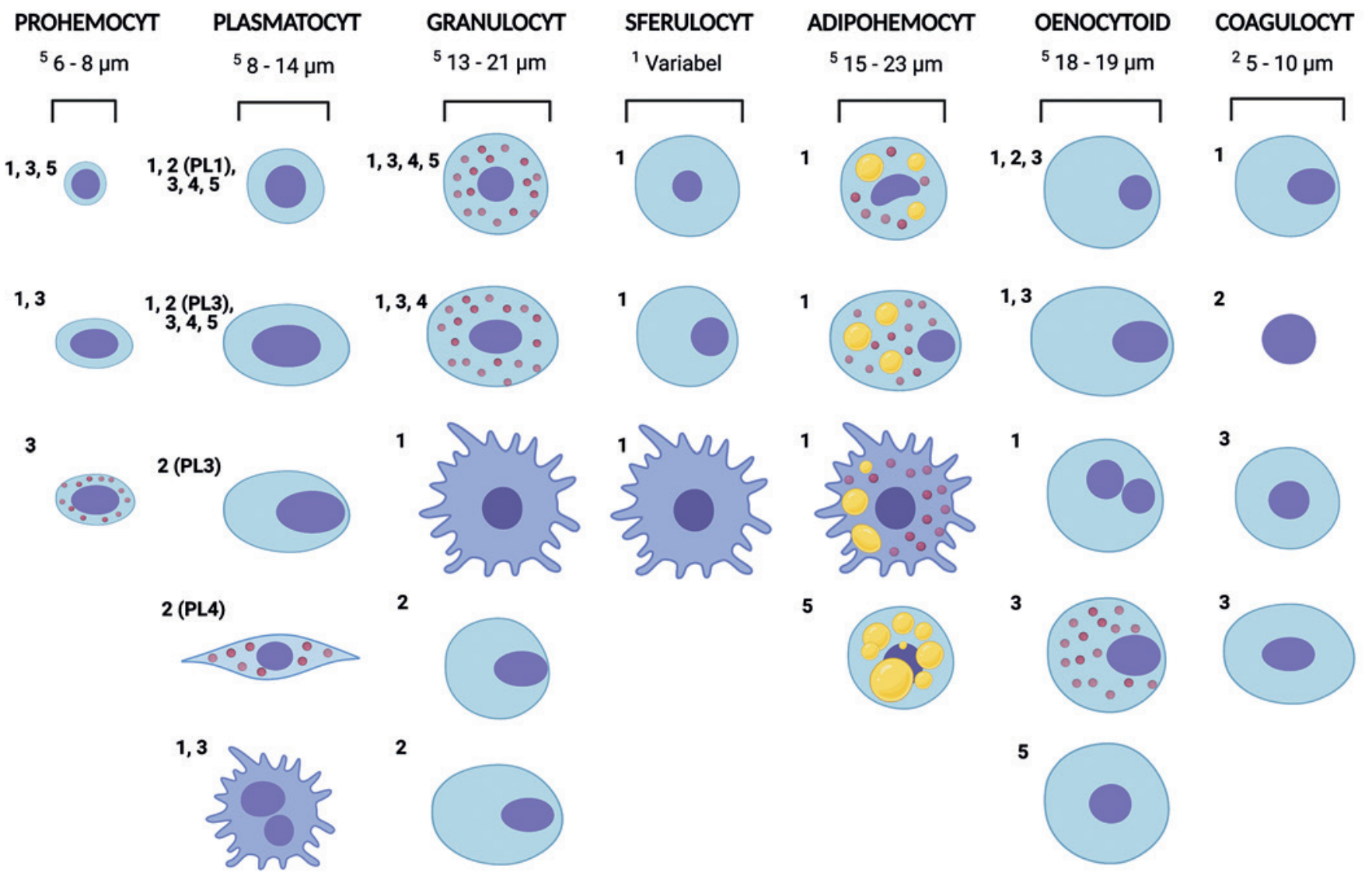

Figuur 1. Grafische voorstelling van de in de literatuur beschreven variatie in hemocytmorfologie, kernmorfologie en hemocytinhoud bij adulte honingbijwerksters op lichtmicroscopie. Gebaseerd op ${ }^{1}$ Gupta (1979), ${ }^{2}$ Van Steenkiste (1987), ${ }^{3}$ Mohandes et al. (2010), ${ }^{4}$ Richardson et al. (2018) en ${ }^{5}$ Yelkovan et al. (2021). De plasmatocyt-subtypes beschreven door Van Steenkiste (1987) worden weergeven als plasmatocyt-subtype 1 (PL1), plasmatocyt-subtypes 3 (PL3), plasmatocyt-subtype 4 (PL 4). Plasmatocyt-subtype 2 is een overgang tussen subtype 1 en 3 ; deze is niet afgebeeld. Granulen worden als rode bollen afgebeeld, lipide druppels als gele bollen. Gemaakt met BioRender.com.

leerd werden. Yelkovan et al. (2021) hebben in een studie de afmetingen van de verschillende honingbijhemocyten in verschillende kasten onderzocht. De resultaten voor adulte werksters worden in Tabel 1 en Figuur 1 weergegeven (Yelkovan et al., 2021). Hieronder volgt een overzicht gebaseerd op een studie van Van Steenkiste (1987) en Gupta (1979), aangevuld met bevindingen uit de recente literatuur. De gebruikte terminologie 'jonge werksters'/"jonge adulten'/'huisbijen' komen in de verschillende studies meestal overeen met werksters jonger dan twintig dagen en 'oude werksters'/'oude adulten'/'foerageerders'/ 'haalbijen' komen meestal overeen met werksters die ouder zijn dan twintig dagen. Echter, dit wordt in de verschillende onderzoeken niet altijd exact beschreven.

\section{Prohemocyten}

Prohemocyten maken minder dan 5\% uit van de totale hemocytenpopulatie bij zeer jonge bijen en minder dan $0,2 \%$ bij oudere bijen. Bij honingbijlarven zouden ze afwezig zijn (Van Steenkiste, 1987; Mohandes et al., 2010). Het zouden stamcellen zijn die post embryonaal verschillende types kunnen vormen. Adulte insecten, inclusief honingbijen, bezitten namelijk geen hematopoëtische klieren, waardoor nieuwe hemocyten via mitose worden gevormd (Hartenstein, 2006; Hillyer, 2016; Hystad et al., 2017). Bij verschillende insecten werd in vitro reeds een transformatie naar plasmatocyten vastgesteld (Jones, 1962; Klowden, 2013). Prohemocyten zijn met een May-Grünwald Giemsa-kleuring heel moeilijk te onderscheiden van plasmatocyten subtype 1 (Gupta, 1979; Van Steenkiste, 1987).

\section{Plasmatocyten}

Plasmatocyten maken meer dan $90 \%$ van de totale hemocytenpopulatie uit bij adulte honingbijen (Van Steenkiste, 1987). De leeftijd werd in die studie echter niet gespecificeerd. Bij jonge werksters maken plasmatocyten ongeveer $90 \%$ van de totale hemocytenpopulatie uit ( Mohandes et al., 2010; Richardson et al., 2018). In een studie van Gábor et al. (2020) werd een stijgende plasmatocytratio gezien gedurende de larvale ontwikkeling (12\% tot $23 \%)$. Bij net uitgekomen werksters blijkt deze ratio nog hoger te liggen, name- 
lijk $77 \%$. Bij oude werksters daalt dit percentage terug tot 51\% (Gábor et al., 2020). Deze trend wordt ook vermeld door Richardson et al. (2018). Deze auteurs stelden echter geen plasmatocyten vast in het larvale stadium. In een studie van Van Steenkiste (1987) werden bij oudere poppen evenmin plasmatocyten vastgesteld; een exacte leeftijd werd niet gegeven. Dat de verhoudingen tussen soorten hemocyten doorheen het leven van insecten veranderen, werd reeds door Jones (1962) vermeld. Hij stelde vast dat dit gepaard gaat met een verandering van het totaal aantal hemocyten, dat hoger is bij larven dan bij poppen en hoger bij poppen dan bij adulten. Gábor et al. (2017) onderzochten de relatie tussen de expressie van Apis mellifera hemolectine (AmHml) door hemocyten met en zonder fagocytosecapaciteit. AmHml wordt tot expressie gebracht door hemocyten die deelnemen aan coagulatie en inkapseling maar niet door hemocyten die betrokken zijn bij fagocytose of melanisatie. Verder werd in een studie van Gábor et al. (2017) de evolutie van fagocyterende en AmHml-expresserende cellen ten opzichte van het totaal aantal hemocyten in de ontwikkeling van de honingbij in beschouwing genomen. De auteurs stelden vast dat bij de honingbijlarve de meerderheid van de hemocyten een fagocyterende functie uitoefenen terwijl 30\% van de hemocyten AmHml tot expressie brengt. In jonge adulten stijgt het aantal AmHml-expresserende cellen tot $80 \%$ en daalt het aantal fagocyterende hemocyten naar 15 tot $20 \%$. In een recentere studie van Gábor et al. (2020) werd het 4E1-antilichaam onderzocht. Dit antilichaam reageert met het eerder vermelde AmHml. Twintig procent van de larvale (L5) hemocyten en $80 \%$ van de jonge adulte hemocyten reageerden met dit antilichaam (Gábor et al., 2020). Deze percentages komen overeen met de eerdere studie van de auteurs uit 2017. De hemocyten werden geïdentificeerd als plasmatocyten. Deze 4E1positieve plasmatocyten werden samengebracht met bacteriën maar fagocyteerden deze niet. Plasmatocyten zijn dus betrokken bij coagulatie en inkapseling. Hystad et al. (2017) toonden echter aan dat plasmatocyten wel fagocyteren. Van Steenkiste (1987) deelde de plasmatocyten na een May-Grünwald Giemsakleuring op in vier verschillende subtypes. De indeling is gebaseerd op het chromatinepatroon, de algemene vorm, de zichtbaarheid van de cytoplasmamembraan, de hoeveelheid cytoplasma en de aanwezigheid van granulen. Plasmatocyt-subtype 1, 3 en 4 worden weergegeven in Figuur 1. Subtype 2 is een overgangstype tussen subtype 1 en 3 . Deze staat niet afgebeeld in Figuur 1. Deze indeling wordt verder echter enkel nog in een studie van de Graaf et al. (2002) en Sapcaliu et al. (2009) gebruikt.

\section{Granulocyten}

Granulocyten maken bij L5-larven bijna 100\% uit van de totale hemocytenpopulatie, bij jonge bijen 10\% en bij oude bijen 1\% (Van Steenkiste, 1987). Deze percentages komen niet overeen met de waarden die Gábor et al. (2020) vonden. De percentages die Gabor et al. (2020) bij de verschillende leeftijden vaststelden, waren: 87\% bij L1-larven, 76\% bij L5-larven, $22 \%$ bij net uitgekomen werksters, jonge koninginnen en darren en $48 \%$ bij oude werksters (geen leeftijd gespecificeerd). Granulocytpercentages van $0 \%$ tot $6,6 \%$ bij huisbijen en $33,6 \%$ tot $67,7 \%$ bij larven van zes tot acht dagen oud werden gerapporteerd (Mohandes et al., 2010; Richardson et al., 2018). Yelkovan et al. (2021) vonden net een meerderheid granulocyten in de derde, vierde en vijfde larvale instar, prepupale, pupale en adulte bijen en dit in alle kasten. Deze resultaten zijn moeilijk met elkaar te vergelijken omdat instar/larvale stadia moeilijk in verband kunnen worden gebracht met leeftijd. Klowden (2013) suggereerde dat bij insecten de granulocytgranulen betrokken zijn bij nutriëntentransport en coagulatie. Deze granulen zouden kunnen worden vrijgegeven op vreemd materiaal in het hemocoel. Volgens Klowden (2013) zouden bij insecten granulocyten kunnen differentiëren naar andere hemocytentypes. Gábor et al. (2020) stelden vast dat monoklonale antistof 4,70-positieve granulocyten kunnen fagocyteren; er werd echter geen percentage gespecificeerd. Opmerkelijk is dat dit antilichaam alle larvale hemocyten en oenocytoïden kan herkennen. Dit suggereert volgens Gábor et al. (2020) een gemeenschappelijke oorsprong van granulocyten en oenocytoïden. Deze werd reeds bij Drosophila aangetoond. Volgens Van Steenkiste (1987) zijn deze cellen moeilijk te onderscheiden van oenocytoïden. Bij May-Grünwald Giemsa-kleuring worden ze herkend aan hun blauw cytoplasma dat gevuld is met verschillende inclusies. Volgens Klowden (2013) zouden granulocyten bij verschillende insecten een belangrijke functie hebben bij de fagocytose van bacteriën maar ook bij de inkapseling door het aantrekken van plasmatocyten die op hun beurt in plaats van rond of ovaal, plat worden en de inkapseling starten.

\section{Sferulocyten}

Sferulocyten worden in de literatuur over honingbijen zelden beschreven. Bij andere insecten maken sferulocyten minder dan 10 tot $15 \%$ van de hemocytenpopulatie uit (Ratcliffe en Rowley, 1979). Volgens een onderzoek van Jones (1962) naar Sarcophaga induceren ze geen coagulatie van het plasma en zouden ze een sterk gespecialiseerde vorm zijn van de granulocyt. Dit type hemocyt werd enkel door Sherif (2017) bij honingbijen aangetoond.

\section{Adipocyten}

Adipocyten worden als een speciale vorm van de granulocyt beschreven (Van Steenkiste, 1987). Hierover bestaat voor verschillende insecten echter geen eensgezindheid en wordt door Klowden (2013) tegengesproken. Deze auteur suggereert dat adipohemocy- 
ten cellen uit het vetlichaam zijn die de hemolymfe stalen bij verschillende insecten kunnen contamineren. Volgens Jones (1962) zijn adipohemocyten geen vetlichaamcellen, ze zijn echter veel kleiner en de nucleus ligt excentrisch. Jones (1962) beschreef hun voorkomen bij enkele Hymenoptera (species werd niet gespecificeerd). Ze worden soms verward met sferulocyten of granulocyten. Behandeling met methanol zou de inclusies in adipohemocyten en bij sommige andere hemocyten (granulocyten en plasmatocyten) kunnen doen oplossen. Hierdoor zouden de hemocyten na Giemsa- of Wright-kleuring moeilijker van elkaar te onderscheiden zijn (Jones, 1962). Deze bevinding toont het belang aan van additionele kleuringen zoals een Sudan-zwartkleuring om de aanwezigheid van vet te bevestigen.

\section{Oenocytoïden}

Oenocytoïden maken slechts een klein deel (minder dan $0,1 \%$ ) van de hemocytenpopulatie uit bij jonge bijen. Bij andere leeftijden (niet nader gespecificeerd) werden geen oenocytoïden vastgesteld (Van Steenkiste, 1987). Mohandes et al. (2010) vonden een gelijkaardig percentage bij jonge werksters. Dit wordt echter weerlegd door Gábor et al. (2020). Zij stelden een constant aantal oenocytoïden $(1 \%)$ over alle ontwikkelingsstadia vast. Volgens de studie van Jones (1962) bij verschillende insecten fagocyteren deze cellen niet. Gábor et al. (2017) toonden aan dat honingbijen oenocytoïden geen AmHml tot expressie brengen maar evenmin fagocyteren. Zoals eerder vermeld werd de afwezigheid van AmHml-expressie in verband gebracht met fagocytose of melanisatie. Later stelden Gábor et al. (2020) vast dat de antistof 2.28-positieve (bindt waarschijnlijk met profenoloxidase op het oppervlak van de oenocytoïde) oenocytoïden geen bacteriën fagocyteren. Er werd echter geen percentage gespecificeerd. Lichtmicroscopisch worden deze cellen herkend door hun bruine kleur (melanine). De aanwezigheid van melanine en dus een functie in de melanisatie zouden kunnen verklaren waarom AmHml-expressie en fagocytose afwezig waren. Volgens Van Steenkiste (1987) en Gábor et al. (2017) zouden deze cellen inderdaad betrokken zijn bij melanisatie. Volgens Klowden (2013), die een algemeen overzicht geeft bij insecten, zijn oenocytoïden ook betrokken bij coagulatie. Oenocytoïden zouden verantwoordelijk zijn voor de melanisatie en verkleuring van hemolymfe bij blootstelling aan de lucht (Gábor et al., 2017). Zoals reeds vermeld wordt een gemeenschappelijke oorsprong van oenocytoïden en granulocyten op basis van het 4.70 antilichaam vermoed (Gábor et al., 2020).

\section{Coagulocyten/ cytocyten}

Over coagulocyten/ cytocyten is, net zoals over sferulocyten, weinig bekend en in de literatuur worden ze zelden beschreven. Het percentage is heel vari- abel naargelang de species maar bij honingbijen zouden deze cellen ongeveer $1 \%$ tot $7 \%$ bedragen. Hun bestaan is, bij honingbijen maar ook bij insecten in het algemeen, nog controversieel (Gupta, 1979; Van Steenkiste, 1987; Mohandes et al., 2010). Bij diverse insecten, waaronder de honingbij, is deze cel een sterk gespecialiseerde vorm van de granulocyt. Coagulocyten worden verantwoordelijk geacht voor de coagulatie van hemolymfe. Andere hemocyten zijn misschien secundair in het coagulatieproces betrokken door de vorming van een netwerk via pseudopodiën of door samenklontering (Jones, 1962; Van Steenkiste, 1987). Dit is in contrast met de bevindingen van Gábor et al. (2017) die coagulatie toewijzen aan plasmatocyten en die het bestaan van coagulocyten niet vermelden.

\section{Gepermeabiliseerde cellen}

Gepermeabiliseerde cellen werden bij honingbijen vastgesteld (Marringa et al., 2014; Burritt et al., 2016; Richardson et al., 2018). Volgens Richardson et al. (2018) lijken deze cellen sterk op granulocyten en plasmatocyten die cellyse of degranulatie vertonen. Ze werden bij honingbij-adulten en -larven aangetoond.

In een studie van Negri et al. (2014) werd het gedrag van hemocyten in vitro bestudeerd. De gevonden cellen werden echter niet in verband gebracht met de reeds uitgevoerde morfologische studies.

\section{CONCLUSIE}

Fundamenteel onderzoek naar de cellulaire immuniteit van de honingbij is van primordiaal belang om verdere bijensterfte te voorkomen. Een bescheiden aantal onderzoeksgroepen heeft reeds geprobeerd om bijdragen te leveren. Traumatische collectiemethoden, gebrek aan standaardisatie en onvoorzichtige extrapolatie (van insecten en leeftijden) hebben echter geleid tot een chaotische en inconsistente indeling van de honingbijhemocyten. Deze kennis is echter noodzakelijk om de bijensterfte te begrijpen en het ontstaan van diverse pathogenen te ontrafelen. Zo zouden selectieprogramma's kunnen worden versneld (Negri et al., 2016; Hystad et al., 2017; de Graaf et al., 2020).

\section{REFERENTIES}

Ali, H., Alqarni, A. S., Owayss, A. A., Hassan, A. M., Smith, B. H. (2017). Osmotic concentration in three races of honey bee, Apis mellifera L. under environmental conditions of arid zone. Saudi Journal of Biological Sciences 24, 1081-1085.

Amdam, G. V., Aase, A. L. T. O., Seehuus, S. C., Kim Fondrk, M., Norberg, K., Hartfelder, K. (2005). Social reversal of immunosenescence in honey bee workers. Experimental Gerontology 40, 939-947.

Ashton-Alcox, K. A., Ford, S. E. (1998). Variability in molluscan hemocytes: A flow cytometric study. Tissue and Cell 30, 195-204. 
Barribeau, S. M., Sadd, B. M., du Plessis, L., Brown, M. J. F., Buechel, S. D., Cappelle, K., Carolan, J. C., Christiaens, O., Colgan, T. J., Erler, S., Evans, J., Helbing, S., Karaus, E., Lattorff, H. M. G., Marxer, M., Meeus, I., Näpflin, K., Niu, J., Schmid-Hempel, R., Smagghe, G., Waterhouse, R. M., Yo, N., Zdobnov, E. M., SchmidHempel, P. (2015). A depauperate immune repertoire precedes evolution of sociality in bees. Genome Biology 16, 1-20.

Borsuk, G., Ptaszyńska, A. A., Olszewski, K., Domaciuk, M., Krutmuang, P., Paleolog, J. (2017). A new method for quick and easy hemolymph collection from apidae adults. PLOS ONE 12, 1-9.

Brandt, A., Gorenflo, A., Siede, R., Meixner, M., Büchler, R. (2016). The neonicotinoids thiacloprid, imidacloprid, and clothianidin affect the immunocompetence of honey bees (Apis mellifera L.). Journal of Insect Physiology 86, 40-47.

Burritt, N. L., Foss, N. J., Neeno-Eckwall, E. C., Church, J. O., Hilger, A. M., Hildebrand, J. A., Warshauer, D. M., Perna, N. T., Burritt, J. B. (2016). Sepsis and hemocyte loss in honey bees (Apis mellifera) infected with serratia marcescens strain sicaria. PLOS ONE 11, 1-26.

Chaimanee, V., Chantawannakul, P., Chen, Y., Evans, J. D., Pettis, J. S. (2012). Differential expression of immune genes of adult honey bee (Apis mellifera) after inoculated by Nosema ceranae. Journal of Insect Physiology 58, 1090-1095.

de Graaf, D. C., Laget, D., De Smet, L., Claeys Boúúaert, D., Brunain, M., Veerkamp, R. F., Brascamp, E. W. (2020). Heritability estimates of the novel trait 'suppressed in ovo virus infection' in honey bees (Apis mellifera). Nature 10, 1-10.

de Graaf, D., Dauwe, R., Walravens, K., Jacobs, F. (2002). Flow cytometric analysis of lectin-stained haemocytes of the honeybee (Apis mellifera). Apidologie 33, 571-579.

de Miranda, J. R., Bailey, L., Ball, B. V., Blanchard, P., Budge, G. E., Chejanovsky, N., Chen, Y. P., Gauthier, L., Genersch, E., De Graaf, D. C., Ribière, M., Ryabov, E., De Smet, L., Van Der Steen, J. J. M. (2013). Standard methods for virus research in Apis mellifera. Journal of Apicultural Research 52, 1-56.

De Smet, L., Hatjina, F., Ioannidis, P., Hamamtzoglou, A., Schoonvaere, K., Francis, F., Meeus, I., Smagghe, G., De Graaf, D. C. (2017). Stress indicator gene expression profiles, colony dynamics and tissue development of honey bees exposed to sub-lethal doses of imidacloprid in laboratory and field experiments. PLOS ONE 12, 1-18.

El Mohandes, S. S., Nafea, E. A., Fawzy, A. M. (2010). Effect of different feeding diets on the haemolymph of the newly emerged honeybee workers Apis mellifera L. Egyptian Academic Journal of Biological Sciences 3, 213-220.

Gábor, E., Cinege, G., Csordás, G., Rusvai, M., Honti, V., Kolics, B., Török, T., Williams, M. J., Kurucz, É., Andó, I. (2020). Identification of reference markers for characterizing honey bee (Apis mellifera) hemocyte classes. Developmental and Comparative Immunology 109, 1-5.

Gábor, E., Cinege, G., Csordás, G., Török, T., Folkl-Medzihradszky, K., Darula, Z., Andó, I., Kurucz, É. (2017). Hemolectin expression reveals functional heterogeneity in honey bee (Apis mellifera) hemocytes. Developmental and Comparative Immunology 76, 403-411.

Gadau, J., Helmkampf, M., Nygaard, S., Roux, J., Simola, D. F., Smith, C. R., Suen, G., Wurm, Y., Smith, C. D. (2012).
The genomic impact of 100 million years of social evolution in seven ant species. Trends in Genetics 28, 14-21.

Gätschenberger, H., Azzami, K., Tautz, J., Beier, H. (2013). Antibacterial immune competence of honey bees (Apis mellifera) is adapted to different life stages and environmental risks. PLOS ONE 8, 1-14.

Genersch, E., Gisder, S., Hedtke, K., Hunter, W. B., Möckel, N., Müller, U. (2013). Standard methods for cell cultures in Apis mellifera research. Journal of Apicultural Research 52, 1-8.

Gourbal, B., Pinaud, S., Beckers, G. J. M., Van Der Meer, J. W. M., Conrath, U., Netea, M. G. (2018). Innate immune memory: An evolutionary perspective. Immunological Reviews 283, 21-40.

Gray, A., Brodschneider, R., Adjlane, N., Ballis, A., Brusbardis, V., Charrière, J. D., Chlebo, R., F. Coffey, M., Cornelissen, B., Amaro da Costa, C. (2019). Loss rates of honey bee colonies during winter 2017/18 in 36 countries participating in the COLOSS survey, including effects of forage sources. Journal of Apicultural Research $58,479-485$.

Gujar, G. T., Kalia, V. K. (2005). Hemocyte diversity of the American bollworm Helicoverpa armigera. Phytoparasitica 33, 17-27.

Guo, Y., Goodman, C. L., Stanley, D. W., Bonning, B. C. (2020). Cell lines for honey bee virus research. Viruses 12, 1-17.

Gupta, A. P. (1979). Hemocyte types: their structures, synonymies, interrelationships, and taxonomic significance. In: Gupta A.P. (editor). Insect Hemocytes Development, Forms, Functions, and Techniques. Cambridge University Press, UK, p. 86-127.

Hartenstein, V. (2006). Blood cells and blood cell development in the animal kingdom. Annual Review of Cell and Developmental Biology 22, 677-712.

Hillyer, J. F. (2016). Insect immunology and hematopoiesis. Developmental and Comparative Immunology 58, 102-118.

Hultmark, D. (2003). Drosophila immunity: Paths and patterns. Current Opinion in Immunology 15, 12-19.

Hystad, E. M., Salmela, H., Amdam, G. V., Münch, D. (2017). Hemocyte-mediated phagocytosis differs between honey bee (Apis mellifera) worker castes. PLOS ONE 12, 1-17.

Jacques, A., Laurent, M., Ribière-Chabert, M., Saussac, M., Bougeard, S., Budge, G. E., Hendrikx, P., Chauzat, M. P. (2017). A pan-European epidemiological study reveals honey bee colony survival depends on beekeeper education and disease control. PLOS ONE 12, 1-17.

Jones, J. C. (1962). Current concepts concerning insect hemocytes. Integrative and Comparative Biology 2, 209246.

Klowden, M. J. (2013). Circulatory systems. In: Physiological Systems in Insects. Third edition, Academic Press, London, UK, p. 365-413.

Kurtz, J., Wiesner, A., Götz, P., Sauer, K. P. (2000). Gender differences and individual variation in the immune system of the scorpionfly Panorpa vulgaris (Insecta: Mecoptera). Developmental and Comparative Immunology 24, 1-12.

Lavine, M. D., Strand, M. R. (2002). Insect hemocytes and their role in immunity. Insect Biochemestry and Biology 32, 1295-1309.

López, J. H., Schuehly, W., Crailsheim, K., RiessbergerGallé, U. (2014). Trans-generational immune priming in 
honeybees. In: Proceedings of the Royal Society B: Biological Sciences 281, 1-8.

Marringa, W. J., Krueger, M. J., Burritt, N. L., Burritt, J. B. (2014). Honey bee hemocyte profiling by flow cytometry. PLOS ONE 9, 39-41.

McMenamin, A. J., Daughenbaugh, K. F., Parekh, F., Pizzorno, M. C., Flenniken, M. L. (2018). Honey bee and bumble bee antiviral defense. Viruses 10, 1-22.

Migdał, P., Murawska, A., Roman, A. (2020). A modified standardized method to extract and store insect hemolymph with use of a glass capillary. Journal of Apicultural Science 64, 165-168.

Negri, P., Maggi, M., Correa-Aragunde, N., Brasesco, C., Eguaras, M., Lamattina, L. (2013). Nitric oxide participates at the first steps of Apis mellifera cellular immune activation in response to non-self recognition. Apidologie 44, 575-585.

Negri, P., Maggi, M., Ramirez, L., Szawarski, N., De Feudis, L., Lamattina, L., Eguaras, M. (2016). Cellular immunity in Apis mellifera: studying hemocytes brings light about bees skills to confront threats. Apidologie 47, 379-388.

Negri, P., Maggi, M., Szawarski, N., Lamattina, L., Eguaras, M. (2014). Apis mellifera haemocytes in-vitro: What type of cells are they? Functional analysis before and after pupal metamorphosis. Journal of Apicultural Research 53, 576-589.

Ratcliffe, N. A., Rowley, A. F. (1979). A comparative synopsis of the structure and function of the blood cells of insects and other invertebrates. Developmental and Comparative Immunology 3, 289-243.

Ravaiano, S. V., Barbosa, W. F., Campos, L. A., Martins, G. F. (2018). Variations in circulating hemocytes are affected by age and caste in the stingless bee Melipona quadrifasciata. Science of Nature 105, 1-8.

Ravoet, J., De Smet, L., Wenseleers, T., de Graaf, D. C. (2015). Vertical transmission of honey bee viruses in a Belgian queen breeding program. BMC Veterinary Research 11, 1-5.

Richardson, R. T., Ballinger, M. N., Qian, F., Christman, J. W., Johnson, R. M. (2018). Morphological and functional characterization of honey bee, Apis mellifera, hemocyte cell communities. Apidologie 49, 397-410.
Saltykova, E. C., Ben'kovskaia, G. V., Gaĭfullina, L. R., Novitskaia, O. P., Poskriakov, A. V., Nikolenko, A. G. (2005). Reaction of Individual Physiological Barriers in Bacterial Infection in Different Races of the Honeybee Apis mellifera. Journal of Evolutionary Biochemistry and Physiology 41, 254-258.

Sapcaliu, A., Rădoi, I., Pavel, C., Tudor, N., Căuia, E., Siceanu, A., Meiu, F. (2009). Research regarding haemocyte profile from Apis mellifera carpatica bee haemolymph originated in the south of Romania. Medicina Veterinara 42, 393-397.

Schmid, M. R., Brockmann, A., Pirk, C. W. W., Stanley, D. W., Tautz, J. (2008). Adult honeybees (Apis mellifera L.) abandon hemocytic, but not phenoloxidase-based immunity. Journal of Insect Physiology 54, 439-444.

Sherif, A. (2017). Influence of Tylosin Drug on Blood Cells of Honeybee Worker Larvae. Journal of Plant Protection and Pathology 8, 271-275.

Van Steenkiste, D. (1987). De hemocyten van de Honingbij (Apis mellifera L.): Typologie, Bloedbeeld en Cellulaire Verdedigingsreacties. Doctoraatsthesis, Doctor in de Wetenschappen, Faculteit der Wetenschappen, Universiteit Gent, België.

VanEngelsdorp, D., Caron, D., Hayes, J., Underwood, R., Henson, M., Rennich, K., Spleen, A., Andree, M., Snyder, R., Lee, K., Roccasecca, K., Wilson, M., Wilkes, J., Lengerich, E., Pettis, J. (2012). A national survey of managed honey bee 2010-11 winter colony losses in the USA: results from the bee informed partnership. Journal of Apicultural Research 51, 115-124.

Yelkovan, S., Arıkan, H., Çakıcı, Ö. (2021). Caste and agerelated changes in circulatory hemocytes of honey bee, Apis mellifera anatolica (Hymenoptera: Apidae). Journal of Apicultural Research 60, 512-521.

Zuk, M., Stoehr, A. M. (2002). Immune defense and host life history. American Naturalist 160, 9-22.

\section{cccreative}

(C) 2022 by the authors. Licensee Vlaams Diereneeskundig Tijdschrift, Ghent University, Belgium. This article is an open access article distributed under the terms and conditions of the Creative Commons Attribution (CC BY) license (http://creativecommons.org/licenses/by/4.0/). 